\title{
Magnesium Acetyl Taurate Prevents Tissue Damage and Deterioration of Prosocial Behavior Related with Vasopressin Levels in Traumatic Brain Injured Rats
}

\author{
Ferda HOSGORLER ${ }^{1}$, Basar KOC ${ }^{1}$, Servet KIZILDAG ${ }^{2}$, Selin CANPOLAT ${ }^{3}$, Asuman ARGON ${ }^{3}$, Asli KARAKILIC ${ }^{1}$, \\ Sevim KANDIS ${ }^{1}$, Guven GUVENDI ${ }^{1}$, Mehmet ATES ${ }^{2}$, Nuri M. ARDA ${ }^{4}$, Nazan UYSAL \\ 'Dokuz Eylul University, School of Medicine, Department of Physiology, Izmir, Turkey \\ ${ }^{2}$ Dokuz Eylül University, School of Medicine, College of Vocational School of Health Services, Izmir, Turkey \\ ${ }^{3}$ Ministry of Health Bozyaka Training and Research Hospital, Department of Pathology, Izmir, Turkey \\ ${ }^{4}$ Dokuz Eylul University, School of Medicine, Department of Neurosurgery, Izmir, Turkey \\ Corresponding author: Ferda HOSGORLER ferda.hosgorler@deu.edu.tr
}

\section{ABSTRACT}

AIM: To investigate the effects of different magnesium forms on tissue damage, cognitive and emotional behavioural impairment after mild traumatic brain injury (TBI).

MATERIAL and METHODS: Rats were divided into 5 groups (control, trauma, magnesium sulphate, magnesium citrate, magnesium acetyl taurate) and following head trauma, empathy-like behaviour, anxiety-like behaviour (elevated plus maze and open field tests), and depression (forced swim test) were measured. The rats were then sacrificed 12 days later. Oxytocin, vasopressin and receptors levels in the amygdala and prefrontal cortex regions were measured. Histopathological damage (with haematoxylin-eosin staining) and apoptosis (with caspase-3 immunohistochemistry) was evaluated.

RESULTS: Following head trauma, anxiety-like behaviour and depression tests did not change; empathy-like behaviour deteriorated on the $3^{\text {rd }}$ day and improved gradually on the $6^{\text {th }}$ and $12^{\text {th }}$ days. Oxytocin, vasopressin and vasopressin v1b receptor levels decreased in the amygdala; morphological damage and apoptosis were significant. Magnesium acetyl taurate effectively ameliorated histopathological deteriorations and improved vasopressin and $\mathrm{v} 1 \mathrm{~b}$ receptor levels in the amygdala. Transient deterioration of empathy-like behaviour was impeded only in magnesium taurate treatment.

CONCLUSION: Magnesium acetyl taurate can be a promising candidate agent to prevent structural and functional damage in traumatic brain injury.

KEYWORDS: Traumatic brain injury, Magnesium, Empathy, Vasopressin, Vasopressin v1b receptor, Rat

ABBREVIATIONS: TBI: Traumatic brain injury, PEG: Polyethylene glycol, Mg: Magnesium, PBS: Phosphate buffer saline, DAB: 3-3-diaminobenzidine, MCP-1: Monocyte chemotactic protein-1, TNF-a: Tumour necrosis factor-alpha, IFN- $\mathbf{~ : ~ I n t e r f e r o n - ~}$ gamma, IL-1ß: Interleukin 1 beta, HE: Haematoxylin-eosin

Ferda HOSGORLER (1) : 0000-0001-6846-5312

Basar KOC (1): 0000-0003-2621-1693

Servet KIZILDAG (1) : 0000-0003-3565-279X

Selin CANPOLAT (D: : 0000-0001-8528-3035
Asuman ARGON : : 0000-0001-7406-0610 Asli KARAKILIC (1): 0000-0001-7788-4949 Sevim KANDIS (1): 0000-0001-8992-7985

Guven GUVENDI (1) : 0000-0002-1858-162X
Mehmet ATES (iD) : 0000-0002-8310-1979

Nuri M. ARDA (1) : 0000-0003-4934-8908

Nazan UYSAL (1) : 0000-0002-2348-7427 


\section{- INTRODUCTION}

$\mathrm{M}$ ild TBI (also known as concussion), occurring in incidents such as motor vehicle accidents and sports injuries, is the most common form of head trauma. Research indicates $43 \%$ of cognitive and $33 \%$ behavioural problems occurred in survivors following mild TBI (6). In mild and moderate TBI, the fronto-temporal lobe and its associated regions (subcortical white matter, basal ganglia, thalamus, amygdala, and hippocampus) are susceptible to damage $(29,48)$. Studies have indicated that following closed head trauma and prefrontal cortex damage, the processes of internalizing the emotions of other people (emotional empathy) and understanding other people's feelings (cognitive empathy) are impaired. This situation leads to emotional withdrawal and disinterest, and disruption of social interactions (12). The deteriorations in cognitive brain functions such as working memory, processing speed, attention, problem solving after head trauma have been investigated extensively, but the effects of head trauma on social behaviour have not been emphasized (31). The impacts of morphological damage following head trauma and the possible changes of neurochemicals on behaviour and social interaction are open to research.

Using magnetic resonance spectroscopy, Vink et.al was the first to demonstrate a decrease in total and free magnesium concentration in brain tissue and it was reported that neurological outcomes improved with magnesium sulphate treatment (43). In the progression of TBI, mechanical damage of nerve fibres (laceration and stretching) occurs during the primary damage processes, followed by ischemia, oxidative stress and mitochondrial damage during secondary damage. Research has shown that reduction of $\mathrm{Mg}^{2+}$ concentration plays a role in the secondary damage processes $(10,43)$. However, in a clinical study of 499 patients with moderate and severe TBI, magnesium sulphate was not effective in improving neurological outcomes (41). When combined with polyethylene glycol (PEG) or when administered in high doses $(600 \mathrm{mg} / \mathrm{kg})$, magnesium sulphate/magnesium chloride were found to yield neurological outcomes $(9,10)$. The limited bioavailability of these forms of magnesium is probably because of insufficient magnesium penetration into brain tissue (30). In our previous study, compared to other forms (magnesium malate, magnesium glycinate), we observed more effective penetration into the brain tissue for magnesium acetyl taurate and magnesium citrate when we implemented the same elemental magnesium doses (3). We observed that these forms passed into the brain tissue more efficiently; however, the effectiveness of these forms on the secondary injury processes in head trauma is open to investigation.

Helping behaviour could be observed in rats when their cage mates experienced stress (35). This behaviour model (also called empathy-like behaviour) is a useful one to demonstrate the relationship between social behaviour and neurochemical influences in the rat brain (47). This model can be used to investigate possible changes in prosocial behaviour following head trauma. The aim of this study is to investigate how emotional states (anxiety, depression) and helping behaviour processes are affected in rats with mild TBI and to compare the efficacy of magnesium forms (sulphate, citrate, acetyl taurate) administered for head trauma.

\section{MATERIAL and METHODS}

\section{Animals and Experimental Procedures}

Ethical approval of the study was granted by the animal experiments ethics committee of our institution (21.02.201833 / 2018). Rats were obtained from the institutional animal laboratory. All experimental procedures were performed by our research team in accordance with the Guide for the Care and Use of Laboratory Animals. One month before the behavioural experiments, the rats were placed in pairs into separate cages. They were accommodated at constant room temperature $\left(22 \pm 2{ }^{\circ} \mathrm{C}\right)$ and humidity $(60 \%)$; they had free access to water and laboratory feed.

Female, 200-250 g, 3-6 months old Sprague Dawley rats were used. Female rats were preferred because females are exposed to mild TBI at a higher rate than males and symptoms and mortality were reported at a higher rate (32). Rats were randomized into 5 groups with 11 animals in each. Histologic evaluations were performed in five animals of each group and chemical evaluations were performed in the other six, behavioural tests were applied to all animals in the groups. The groups were designated as control: no drug and no trauma group, trauma: head trauma group, Mg sulphate: magnesium sulphate treated group after head trauma, $\mathrm{Mg}$ citrate: magnesium citrate treated group after head trauma, and $\mathrm{Mg}$ taurate: magnesium acetyl taurate treated group following head trauma. When the experiments began, all the rats and their cage mates were placed into an empathy box for 5 minutes for 12 days and learned to rescue their cage mates. The motor functions of the rats were evaluated in a rotarod apparatus on the $10^{\text {th }}, 11^{\text {th }}$ and $12^{\text {th }}$ days of the experiments. On the $13^{\text {th }}$ experimental day, head trauma was administered to all groups except the control group. The administration of magnesium compounds was performed during the next 12 days following head trauma and empathy-like behaviour and motor performance were evaluated on the post-trauma $3^{\text {rd }}, 6^{\text {th }}$, $12^{\text {th }}$ days. On the $12^{\text {th }}$ day, after the last empathy test, anxiety measurements and depression measurements were evaluated (Figure 1). The animals were sacrificed immediately after the behavioural experiment.

\section{Pharmaceutical Applications}

In this study, a Ketamine (Ketasol 10\%, Richter Pharma AG, Wels, Austria) and Xylazine (Alfazyne 2\%, Alfasan International BV, Woerden, Holland) mixture at a dose of $40 / 6 \mathrm{mg} / \mathrm{kg}$ was applied for head trauma. This medication is preferred because it provides effective analgesia following head trauma and does not increase cerebral blood flow or intracranial pressure $(18,22,34)$. Magnesium salts were administered to contain elemental magnesium at $125 \mathrm{mmol} / \mathrm{kg}(16,17)$. Magnesium sulphate was administered to rats at a dose of $30 \mathrm{mg} / \mathrm{kg}$ intramuscularly, magnesium citrate at a dose of $27 \mathrm{mg} / \mathrm{kg}$ perorally by gavage and magnesium acetyl taurate at a dose of $50 \mathrm{mg} / \mathrm{kg}$ perorally by gavage. 


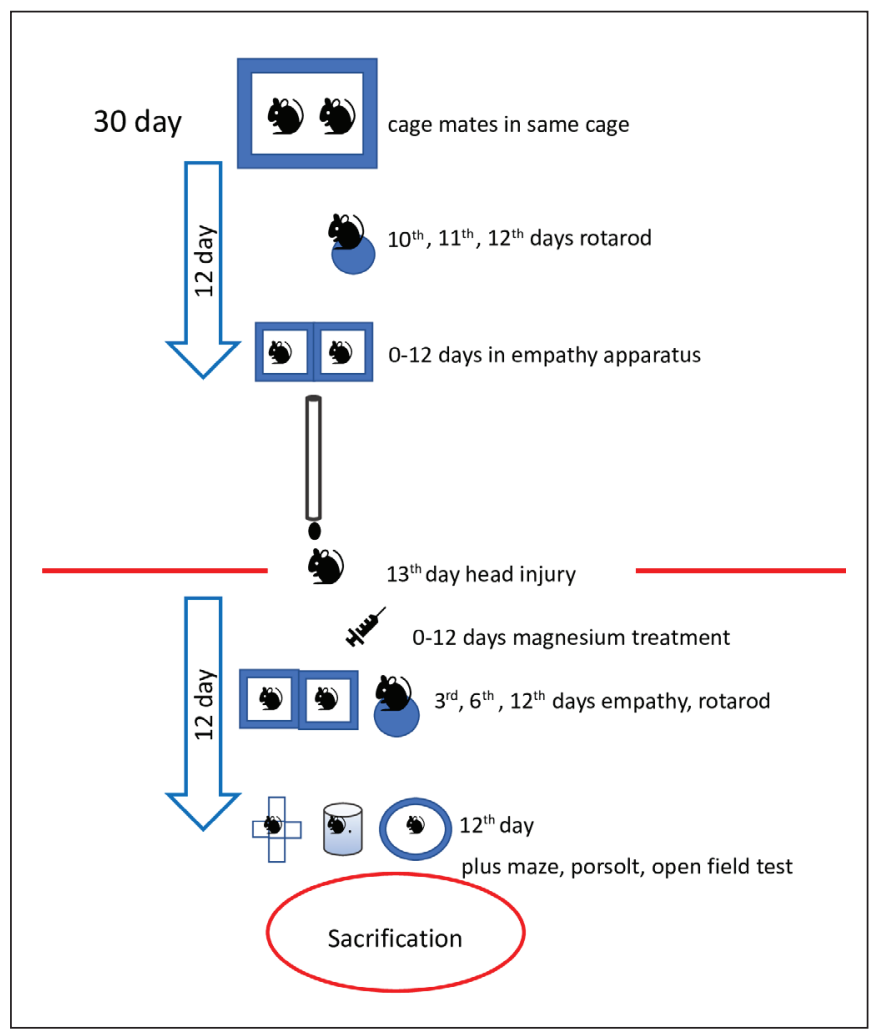

Figure 1: Flow chart of experiments. The procedures performed before and after head injury.

\section{Head Trauma Protocol}

After completion of familiarization and learning experiments, on day 13, head trauma was applied to the rats. The modified Marmarou weight-drop model that produces diffuse axon damage was performed $(28,33)$. A steel tube (height of 1 meter) which allowed a free fall of $450 \mathrm{~g}$ brass weight was used and focused on the desired point in the skull (Figure 2A). A skull protective metallic (copper-nickel composite) disc $(10 \times 3 \mathrm{~mm})$ was attached between the coronal and lambdoid sutures on the rat's skull. The disk intended for the weight to hit was aligned to the bottom of the tube (Figure 2B). The rats were fixed on a 30x20 cm cardboard piece and placed on the plexiglass box $(40 \times 80 \mathrm{~cm})$, that covered with aluminium foil. A soft sponge was laid on the base of box. The aluminium foil allowed the rats to fall freely into the sponge. In this manner, a counter impact effect secondary to the first impact was prevented. Following head trauma, the disks were removed from the skulls of rats and the scalps were sutured.

\section{Behaviour Experiments}

The behavioural experiments were recorded with the camera and EthoVision XT software (Noldus Information Technology Inc., Leesburg, VA, USA). The experiments were performed in the soundproof laboratory room between 09.00-12.00 hours.

\section{Empathy-Like Behaviour}

Empathy-like behaviour in rats can be observed in the empathy apparatus which is a $450 \times 450 \times 900 \mathrm{~mm}$ plexiglass
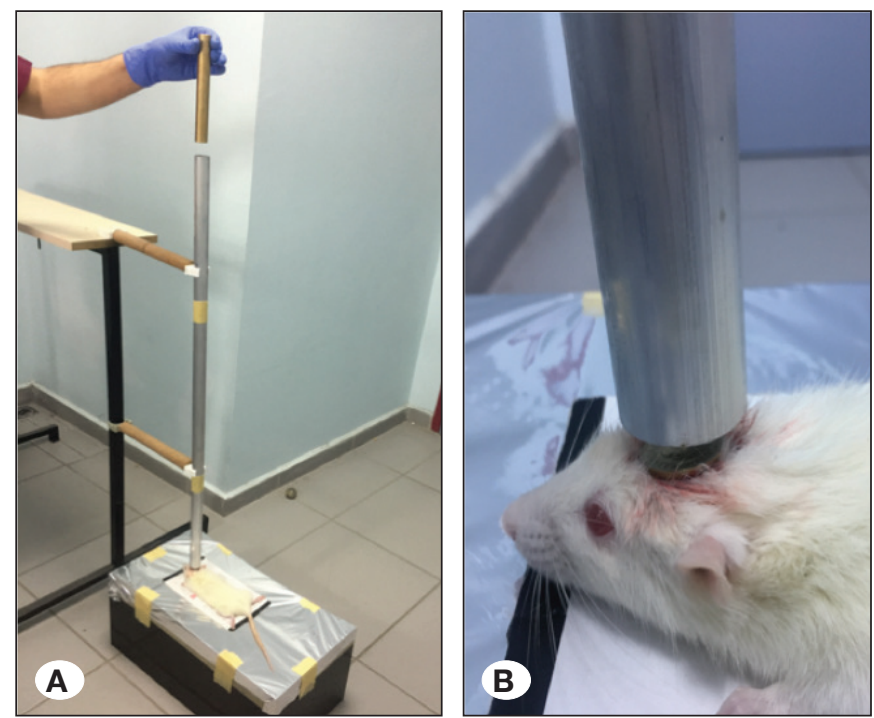

Figure 2: Head trauma experiments. A) Aluminium foil was affixed to the Plexiglass box. The impact effect tears the foil and the rat falls into the box. B) The secondary impact effect is diminished with the helmet affixed to the rat skulls.

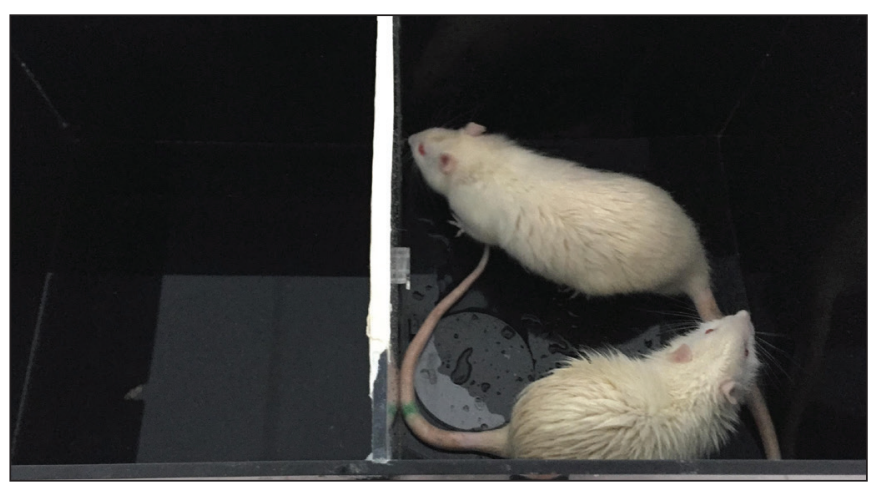

Figure 3: Empathy-like behavior test box. In the empathy apparatus, the observer rat in the dry chamber rescues the cage mate in the water-filled chamber by opening the rescue door.

box comprised of two compartments, one full of water, the other dry, and a transparent partition with a door between the two compartments. The door can be opened only from the dry side $(23,47)$. The observer cage mate in the dry chamber can rescue the rat under stress in the water-filled compartment by opening the door (Figure 3). The rats were observed for 300 seconds and the rescue times of their cage mates were recorded. The experiments were repeated for 12 days prior to the trauma in order to enable the animals to learn how to open the door. It was accepted that the rat who rescued its cage mate by opening the door in 300 seconds demonstrated helping behaviour.

\section{The Rotarod Test}

The rotarod test provides an evaluation of balance and motor control. The apparatus measures the ability of the experimental animals to stand upon a rotating shaft. Three days before the 
trauma, the rats learned to walk on the rotarod assembly. The rats ran at $4 \mathrm{rpm}$ for 300 seconds and the times they fell from the shaft were recorded.

\section{The Elevated Plus Maze Test}

An apparatus, a device with 4 arms (2 open, 2 closed arms) located $50 \mathrm{~cm}$ above the ground, is used to determine anxiety-like behaviour. The rats were placed on the central platform $(5 \times 5 \mathrm{~cm})$ in the centre of the device. The time the rats spent in the closed and open arms (long of $50 \mathrm{~cm}$ ) and the number of entries into these arms in a 300 second duration were recorded. The rats with high anxiety levels spend more time in a closed area.

\section{The Open Field Test}

The apparatus is used to test anxiety-like behaviour and is comprised of a black coloured plexiglass consisting of a $1 \times 1$ meter square area. The test animal was placed in the middle of the field and the movements within the field were recorded with the camera for 300 seconds during the test. The time the rats spent on the edges and in the centre of the area, and the contact times with the walls of the area (thigmotaxis) were measured. An increase in the time spent on the edge of the area and the time in contact with the walls was accepted as a sign of anxiety.

\section{The Forced Swim Test (Porsolt Test)}

This is used to evaluate depression behaviour. A transparent cylindrical container was filled with water to a depth of 50 $\mathrm{cm}$. The rats were immersed into the water and swimming effort behaviour and immobilization times were recorded over 300 seconds. Increased periods of immobility in water were accepted as signs of depression.

\section{Euthanasia and preparation of blood and tissue samples}

After head trauma at the $12^{\text {th }}$ day, the rats were euthanized under $\mathrm{CO}_{2}$ inhalation anaesthesia which has a fast and shortterm anaesthesia effect in rats (25). The rats were euthanized by decapitation; blood samples, which underwent chemical analysis in each group, were obtained by thoracotomy and cardiac puncture of the right heart ventricle. For ELISA measurements, brain tissues were removed and stored at $-85^{\circ} \mathrm{C}$ in a refrigerant. Blood samples were centrifuged at 1,000 $\mathrm{g}$ for 10 minutes and their serums were collected and stored at $-85^{\circ} \mathrm{C}$. The other rats, which were evaluated for histological analysis, underwent thoracotomy and perfused transcardiacly through left ventricular catheterization with isotonic saline. The right atrium was incised, and perfusion continued until all the blood was cleared. Immediately afterward, the left ventricle was infused with $4 \%$ paraformaldehyde in phosphate buffer saline (PBS) for 15 minutes. The brain was gently removed from the skull and kept in $40 \%$ paraformaldehyde for 48 hours until paraffin embedding.

\section{Biochemical Measurements}

Frozen samples of the brain tissue were weighed and homogenized with steel beads using BioSpec Mini-Beadbeater-16 (BioSpec Products Inc., USA) in 10 volumes of PBS $(\mathrm{pH}: 7.4)$ and centrifuged at $5000 \mathrm{~g}$ for $15 \mathrm{~min}$ at $4^{\circ} \mathrm{C}$. The supernatants and serums were used for biochemical analyses.
In this study, the ELISA measurements were obtained using rat Arginine Vasopressin Elisa Kit (Cat No: E1873Ra, Bioassay Technology Laboratory, Shanghai, China), rat Oxytocin Elisa Kit (Cat No:E1216Ra, Bioassay Technology Laboratory, Shanghai, China), rat Oxytocin Receptor Elisa Kit (Cat No: E1476Ra, Bioassay Technology Laboratory, Shanghai, China), rat Vasopressin V1a Receptor Elisa Kit (Cat No: E1477Ra, Bioassay Technology Laboratory, Shanghai, China), rat Vasopressin V1b Receptor Elisa Kit (Cat No: E1478Ra, Bioassay Technology Laboratory, Shanghai, China), and rat Corticosterone ELISA kit (Cat No:E0496Ra, Bioassay Technology Laboratory, Shanghai, China). BCA protein Assay kit (Catalog Number 23227, PierceTM, U.S.A.) was used for protein analysis. Assay procedure was completed in accordance with the kit protocol. All results were calculated with mg protein per tissue. Absorbency changes were calculated with microplate reader (ELx800, BioTek Instruments, Inc., Winooski, VT, USA) at $450 \mathrm{~nm}$ for ELISA kits and at $560 \mathrm{~nm}$ for protein assay kit.

\section{Histology}

Formalin-fixed brain tissues were blocked with paraffin and sliced $5 \mathrm{~mm}$ thick with a rotary microtome (Leica RM2245, Germany). Sections were deparaffinized, hydrated, and stained with haematoxylin and eosin (HE) and assessed at $\times 20, x 40$ magnification. Morphological changes in cells, extracellular oedema and pericellular gaps were evaluated qualitatively by two pathologists using a BX51 Olympus microscope (Olympus, Tokyo, Japan).

\section{Immunohistochemistry}

Coronal sections of $8 \mathrm{~mm}$ thickness were prepared, deparaffinated and washed. The sections underwent treatment for dyeing process with citrate buffer (Cat No: AP-9003-125 LabVision) (10 mM at $\mathrm{pH}: 6$ ) and then processed with $\% 3 \mathrm{H}_{2} \mathrm{O}_{2}$, serum blocking solution, 1/100 polyclonal active caspase-3 antibody (Cat No: AB3623, Merck Millipore, USA). Finally, after incubation with biotinylated IgG and streptavidin conjugated to horseradish peroxidase, sections were stained with 3-3-diaminobenzidine (DAB) (Roche Diagnostics, Mannheim, Germany) and with Mayer haematoxylin solution. In the evaluation of apoptosis, apoptotic cells were counted at 10 different x40 magnification regions and their ratio to total cell numbers were recorded. Apoptotic bodies (a morphologic hallmark of apoptosis), nuclear fragmentation and the pyknotic nucleus were evaluated. Tissue evaluation was performed using the BX51 Olympus microscope (Olympus, Tokyo, Japan) and images were recorded with video camera system with DP Controller and DP Manager software (Olympus America, Melville, USA).

\section{Statistical Analysis}

Statistical analyses were performed via the SPSS 22 (IBM, Turkey) program. Chemical and behaviour measurement data are provided in column graphs as mean \pm standart deviation (SD). Normality was determined with the Shapiro Wilk test. One-way ANOVA was used for data with normal distribution; two-way repeated measures ANOVA was used to determine the differences between groups on different days of behaviour measurements. One-way repeated measures ANOVA test 
was used to determine the differences of behaviour at varying days within each group. The Tukey test was used in post hoc analysis. Kruskal Wallis and the post hoc Mann Whitney $U$ test were used for data which did not correspond to normal distribution. The correlation analysis was performed using the Pearson correlation analysis. The Bonferroni correction was performed in SPSS for $p$ values and $p<0.05$ was considered significant.

\section{RESULTS}

Oxytocin and vasopressin measurements of the prefrontal cortex displayed no significant differences but in the amygdala there were significant differences between the groups $(F(4,20)=4.57, p=0.009$ for oxytocin and $F(4,23)=10.49$, $\mathrm{p}<0.0001$ for vasopressin). In the inter-group evaluation in the amygdala, compared to the control group, oxytocin and vasopressin levels of the trauma group were significantly decreased $(p=0.011, p=0.006$ respectively, Figures $4 A, B)$. Compared to the trauma group, vasopressin levels of the $\mathrm{Mg}$ taurate group had increased $(p=0.001$, as illustrated in Figure 4B).

When oxytocin and vasopressin receptors (v1a, v1b) were examined in the amygdala and prefrontal cortex, a significant difference was found only in the $\mathrm{v} 1 \mathrm{~b}$ receptor levels in the amygdala $(F(4,21)=7.17, p=0.001)$. In post hoc analysis, $v 1 b$ receptor levels of the $\mathrm{Mg}$ taurate group were significantly higher than all other groups $(p=0.004$ for control group, $p=0.002$ for trauma group, $p=0.002$ for sulphate group, $p=0.011$ for citrate group, Figure 4C).

When empathy-like behaviour measurements were examined, there was no significant difference between groups at the end of the learning experiments (Figure 5A). In the comparison of before and after trauma, there was a significant difference between groups in terms of door opening durations in different time points (pre-trauma, post-trauma $3-6-12^{\text {th }}$ day) in the repeated measures two way ANOVA test $(F(3,81)=36.13$, $p<0.0001$ for day effect, $F(4,27)=5.45, p=0.002$ for group effect, $F(12,81)=6.08, p<0.0001$ for interaction effect). Significant differences between the groups were apparent only at day 3 $(F(4,27)=7.69, p<0.0001$, Figure 5B and Figure 6). On the third post-traumatic day, the door opening time was significantly longer in the both trauma and $\mathrm{Mg}$ sulphate group than in the control group $(p=0.006, p=0.004$ respectively, as illustrated in Figure 6). In the Mg taurate group, the door opening duration was significantly lower than trauma group ( $p=0.01$, Figure 6). There was no significant difference between the trauma, Mg sulphate and $\mathrm{Mg}$ citrate groups at day 3 .

There was a moderately significant negative correlation between both amygdala vasopressin and $\mathrm{v} 1 \mathrm{~b}$ receptor levels and door opening times measured on the post-traumatic 3rd day $(r=-0.661, p<0.0001$ for vasopressin, $r=-0.567$, $p=0.003$ for $v 1 b$, Figure $7 A, B)$. There was no difference in the measurements of the rotarod test between the pre- and posttraumatic periods. The open-field tests, elevated plus maze tests and forced swim tests indicated no differences. The plasma corticosterone levels measured as an anxiety marker were not significantly different between the groups.
Histologically, the cells of the control group exhibited normal morphology and there were no signs of oedema or necrosis in the HE stained sections. In the trauma group,

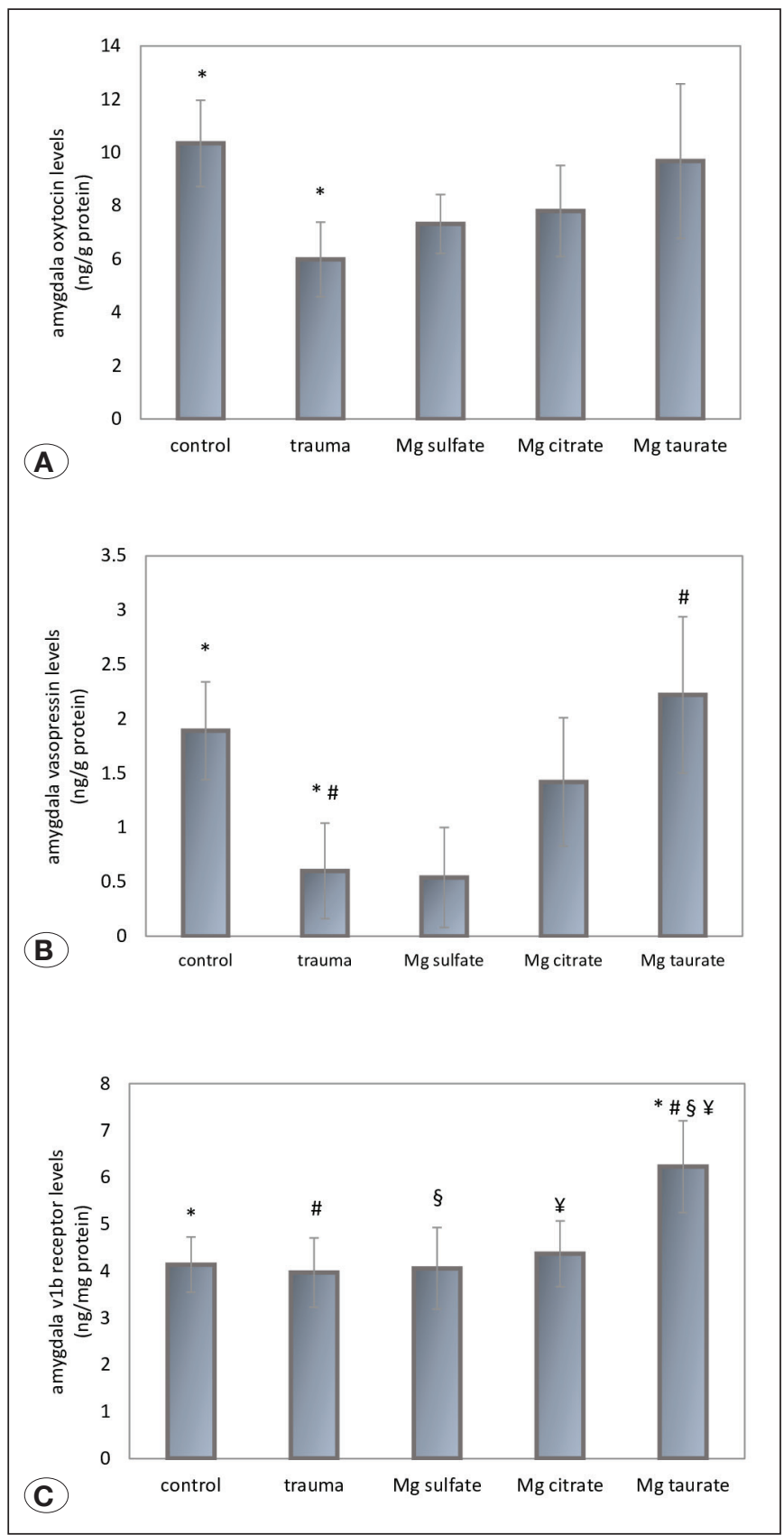

Figure 4: Oxytocin and vasopressin levels in the amygdala. A) Compared to the control group, amygdala oxytocin levels decreased in the trauma group (Mg: magnesium, $p<0.05$ ). B) Amygdala vasopressin levels decreased significantly in trauma group compared to the control group. Amygdala vasopressin levels increased in the $\mathrm{Mg}$ taurate group compared to the trauma group (Mg: magnesium, ${ }^{*} \mathrm{p}<0.01$ ). C) $v 1 \mathrm{~b}$ receptor levels increased in the Mg taurate group compared to control, trauma, Mg sulphate and Mg citrate groups (Mg: magnesium, " ${ }^{~} \$ p<0.01$, $\left.{ }^{\ddagger} p<0.05\right)$. 


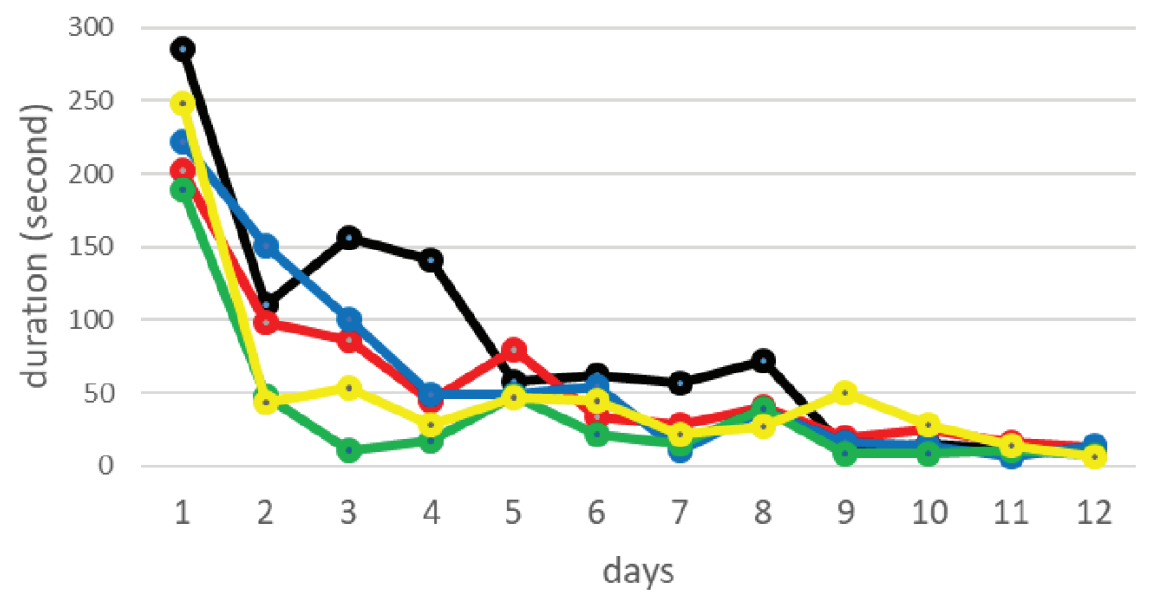

A - Control - trauma - Mg sulfate - Mg citrate $\rightarrow$ Mg taurate

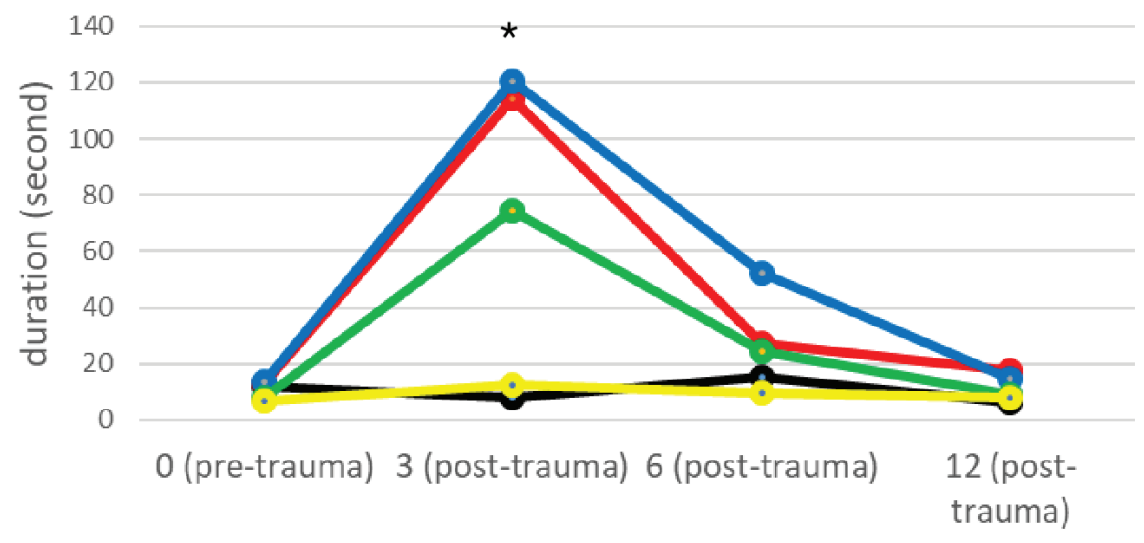

days

B -control - - - trauma $=$ Mg sulfate - Mg citrate - Mg taurate

Figure 5: Door opening durations in groups before and after head trauma. A) All the rats in the pre-trauma phase learned to open the doors within 12 days.

B) A significant difference between the groups was detected only on the $3^{\text {rd }}$ day (Mg: magnesium, $p<0.0001)$.

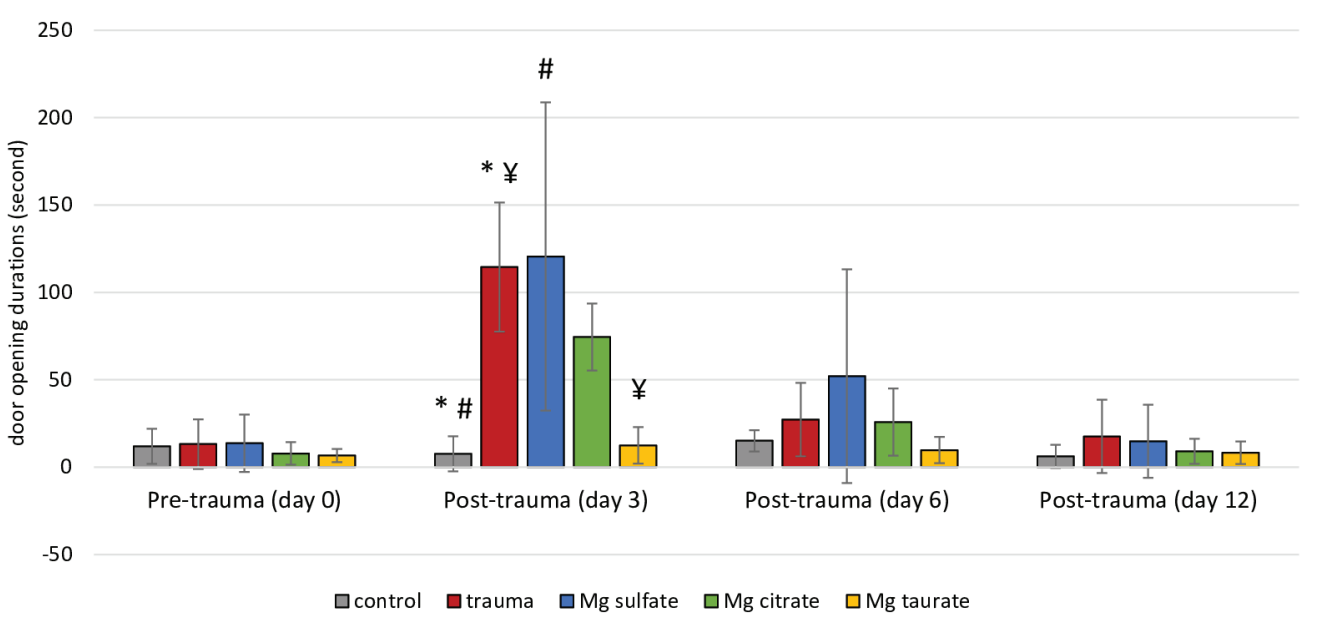

Figure 6: Door opening durations between groups in the different time points. Door opening durations increased significantly in the trauma and $\mathrm{Mg}$ sulphate groups on day 3 compared to the control group. Door opening durations improved gradually on day 6 and day 12 (Mg: magnesium, ${ }^{*} p<0.01$, $¥ p<0.05)$. 

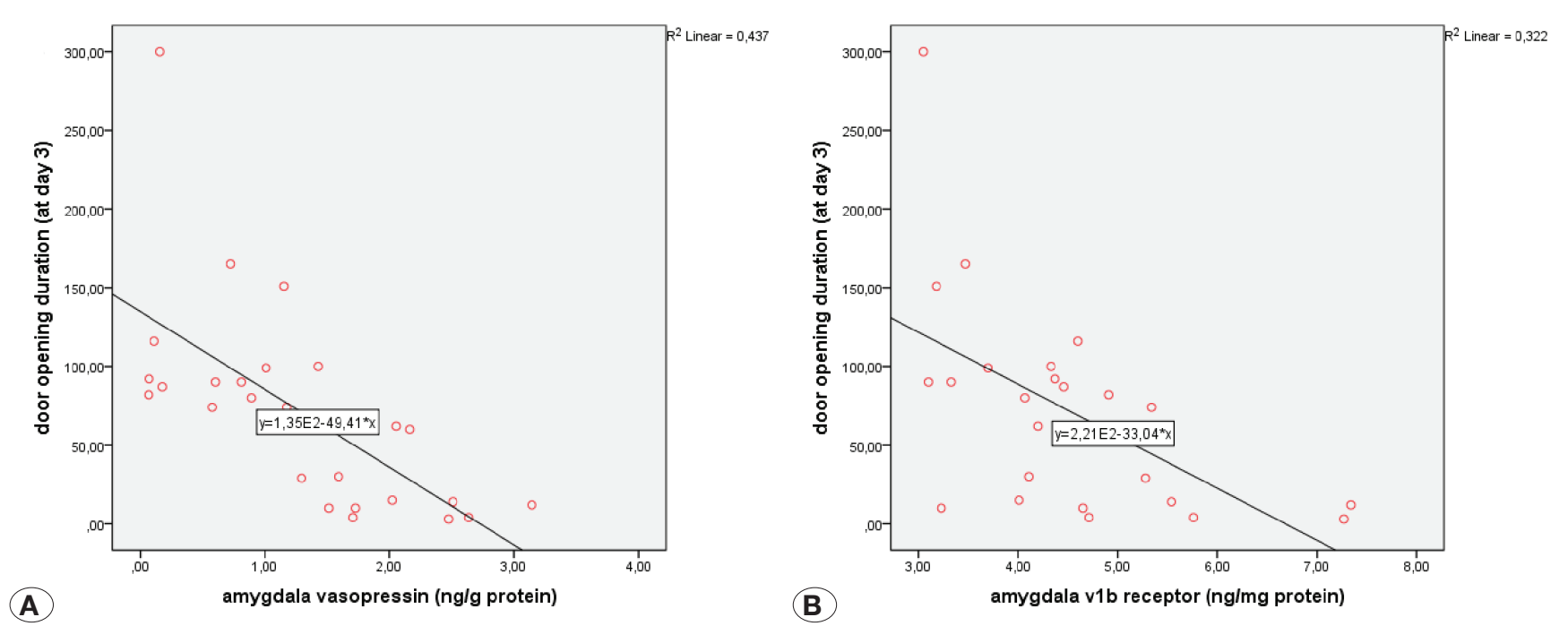

Figure 7: The relationship between the door opening durations and vasopressin and v1b receptor levels. A) A moderate negative correlation was found between vasopressin levels and door opening times on day 3. B) There was a low negative correlation between durations and $\mathrm{v} 1 \mathrm{~b}$ receptor levels.

diffuse oedema of the brain tissue and extracellular cavities in large areas, deterioration of cell contours and swelling of the cells, nuclear pyknosis and necrosis were observed. In the $\mathrm{Mg}$ taurate and $\mathrm{Mg}$ citrate groups, mild oedema and a few extracellular cavities, a small number of pyknotic nuclei and shrunken cells were observed. In the Mg sulphate group, pyramidal and granular cells with pyknotic nuclei and morphological impairments were fewer than the trauma group and more prominent than the other groups (Figure 8A-E). Immunohistochemical examination showed no pathological nuclear caspas-3 staining in the control group. In the trauma group, cells with nuclear fragmentation, disrupted cell contours and apoptotic bodies were more common than the other groups (Figure 9). The number of cells of caspase-3 with nuclear involvement demonstrated significant differences between the groups $(F(4.20)=11.79, p<0.0001)$. Compared to the control group, the number of apoptotic cells was significantly increased in all groups $(p<0.0001$ for trauma, $p=0.001$ for $M g$ sulphate, $p=0.001$ for Mg citrate, $p=0.02$ for $\mathrm{Mg}$ taurate groups). Compared to the trauma group, apoptotic cells were significantly diminished in the Mg taurate group $(p=0.039$, Figure 10).

\section{DISCUSSION}

In this mild trauma model, we aimed to create diffuse axonal damage without causing significant focal damage. The fixation of the animal or its head, and the presence of soft or hard ground under the animal, affects the severity, type and neurological consequences of the damage (42). In the mild TBI model we created, the impact effect was distributed diffusely into the head by the helmet and the secondary impact effect was alleviated by the free movement of the animal. In the rotarod assembly, we did not detect loss of motor cortex function and imbalance.
The previous measurements in experimental TBI models mostly focused on cognitive abilities and anxiety-depression assessment. These studies indicated that cognitive deficits, anxiety-like behaviour and depression do not occur in acute and chronic periods following TBI $(27,37)$. Our anxiety-like behaviour and depression measurements were consistent with the results of these studies. Research has stated that loss of emotional empathy occurs in TBI victims $(11,44,45)$. Empathy-like behaviour in rats is a type of pro-social behaviour that exhibits helping behaviour $(23,35,47)$. We observed that helping behaviour continued following TBI but the start duration of helping in the empathy box was significantly prolonged on the post-trauma $3^{\text {rd }}$ day. Delays in helping behaviour on the post-trauma third day in the trauma group may be related to the reduction of hormone levels in the amygdala. In our previous studies, we observed changes in the oxytocin and vasopressin levels in this region associated with empathy-like behaviour $(23,47)$.

We investigated the relationship between the prolonged durations to initiate helping and low hormone levels. We found a negative correlation between the durations of starting to help, and both vasopressin levels and vasopressin v1b receptor levels of the amygdala. We have demonstrated that helping behaviour in traumatic rats is accelerated by high vasopressin and $\mathrm{v} 1 \mathrm{~b}$ receptors in the amygdala. In some clinical studies, vasopressin has been shown to correlate with personal distress and emphatic concern levels (15, 40). Low vasopressin levels following head trauma may play a role in decreasing empathic concern. Vasopressin was demonstrated to be effective in increasing vocalization signals generating a call for help among female monkeys (21). Low vasopressin levels may delay helping behaviour; this may be due to the reduction of empathic concern and the reduction in vocalization signals. Studies of the behavioural effects of the 

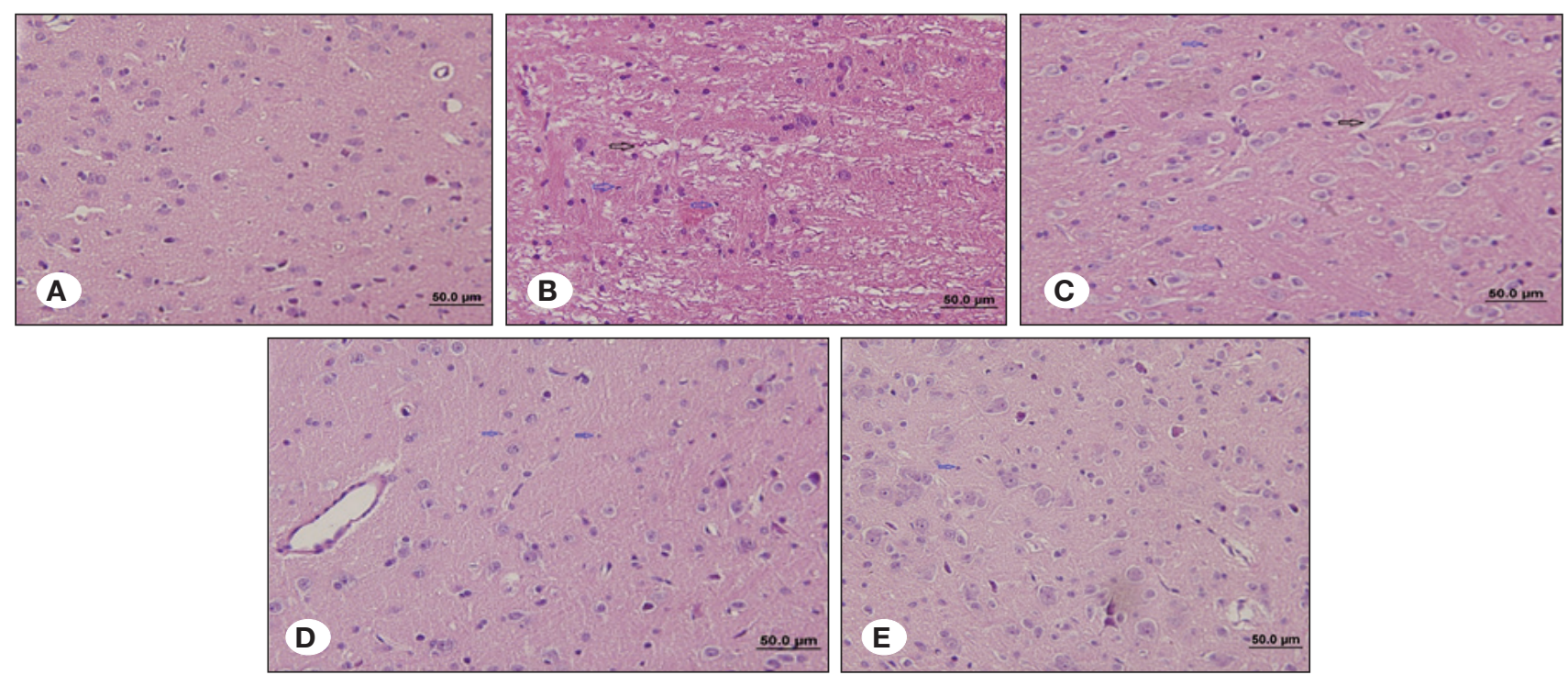

Figure 8: Histological changes in haematoxylin and eosin (HE)-stained brain sections. A) Normal morphology of pyramidal, granular and glial cells were seen in the sections of control group. B) Diffuse oedema in brain tissue of trauma group and extracellular cavities (black arrow) were observed in large areas. Cells showed signs of swelling, cavitation and necrosis. Shrunken neurons were seen with nuclei pyknosis (blue arrow). Cells with distorted cell contours were common. C) Mg sulphate group showed decreased oedema in brain tissues compared to trauma group but more prominent oedema and gaps in extracellular areas (black arrow) compared to other groups. Pyramidal and granular cell density with pyknotic nuclei and degenerate morphology was decreased compared to the trauma group. D) In the Mg citrate group, lighter oedema, fewer pyknotic nuclei and shrunken cells (blue arrow) were observed compared to the trauma group. E) the Mg taurate group showed decreased oedema and extracellular cavities compared to the trauma group. Cells with pyknotic nuclei and impaired cell contours were less frequent than the trauma group (blue arrow) (HE: haematoxylin-eosin, all images were presented at X40 magnification).
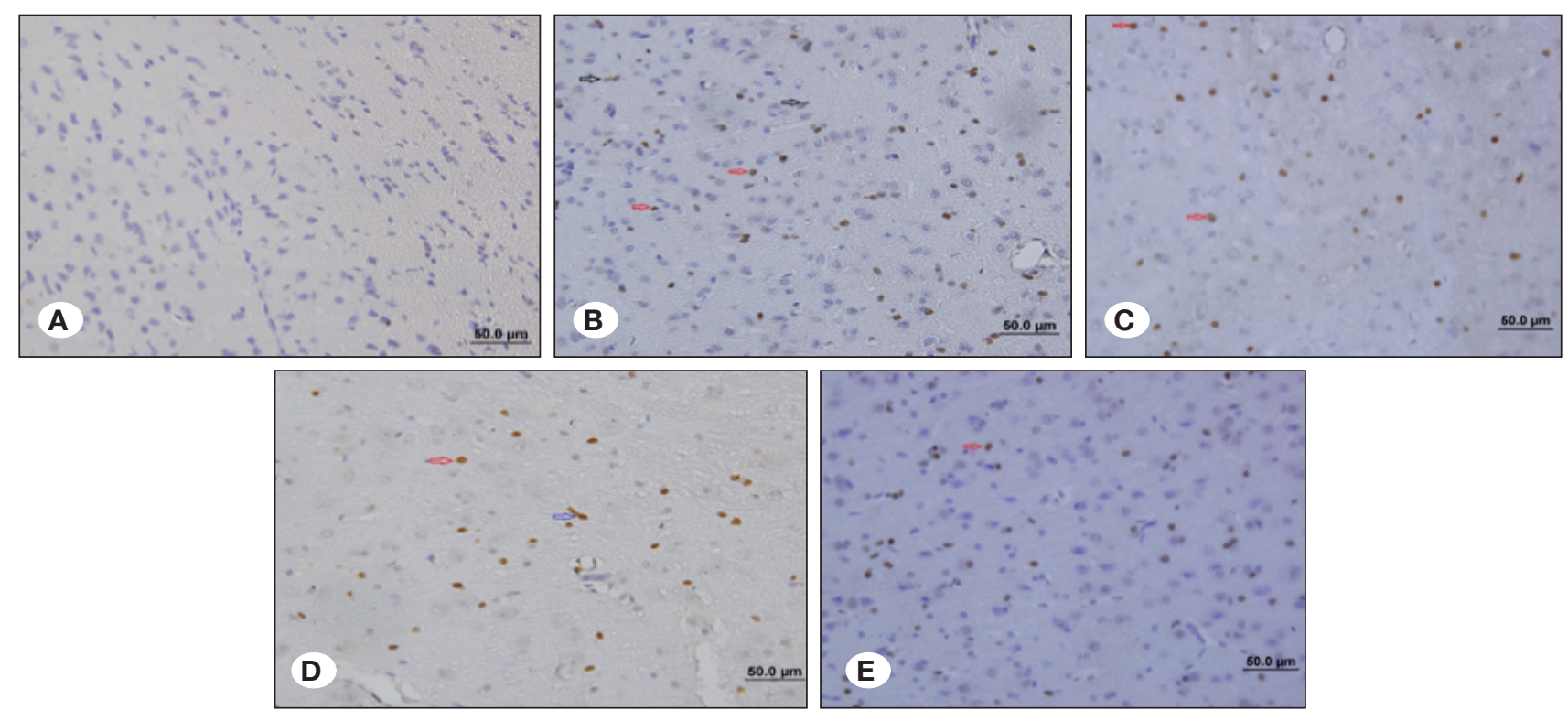

Figure 9: Immunohistochemistry examination of active caspase-3 in brain sections. A) Cytoplasmic pale stained caspase-3 stained cells were observed in the control group in a very rare area. B) Caspase-3 positive cells were observed intensely in the frontoparietal cortex, hippocampus, thalamus and other subcortical regions in the trauma group. The nuclear density of Caspase-3 was increased compared to the other groups. Cells with apoptotic bods (black arrow) and nuclear fragmentation (red arrow) with impaired cell contours were present in all areas. C) In the Mg sulphate group, cells with fragmented nuclei and nuclear caspase-3 staining (red arrow) were more common in the parietal- frontal cortex and subcortical regions. D) In the Mg citrate group, cells with fragmented nuclei and nuclear caspase-3 positive staining (red arrow) were observed in all regions but the density of these cells was less than the trauma group. Segmented axons were observed (blue arrow). E) In the Mg taurate group, segmented axon degenerations, fragmented nuclei and caspase-3 positive cells (red arrow), which were less prominent than the trauma group were observed. All images are in X40 magnification. 


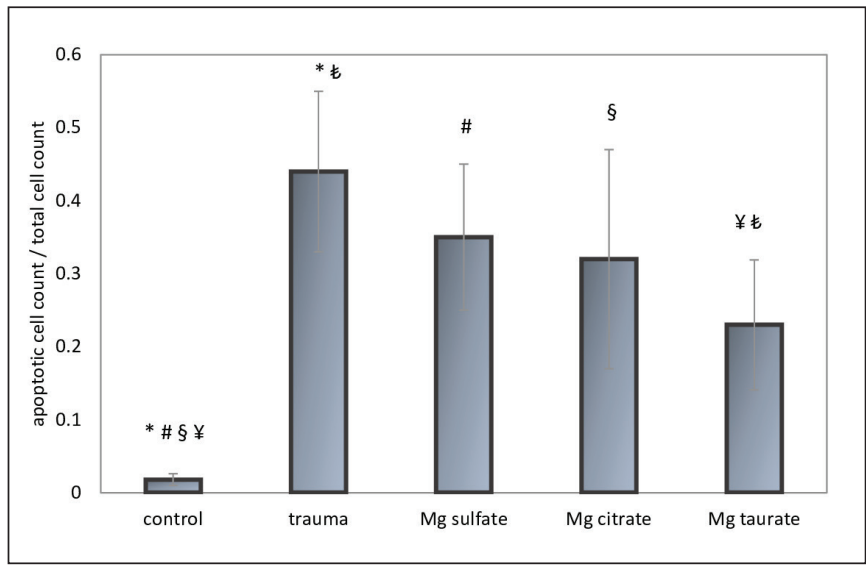

Figure 10: The count of apoptotic cell in groups. The ratio of apoptotic cells to total cell number increased in all groups compared to the control group. This ratio decreased in the $\mathrm{Mg}$ taurate group compared to the trauma group (Mg: magnesium, $\left.\mathrm{p}<0.0001,{ }^{\#} \mathrm{p} p<0.01,{ }^{*} \mathrm{p}<0.05\right)$.

v1b receptor are limited. Genotype and gene polymorphism analyses revealed the relationship between the $\mathrm{v} 1 \mathrm{~b}$ receptor and emotional processes (empathic concern, emotional empathy, prosocial behaviour and mood disorders) $(39,46)$. Our results support the role of the vasopressin-v1b receptor pathway in the emotional processes and helping behaviour. In an unpublished study, we observed a positive correlation between the duration of help (exhibited in the empathy box) and the $\mathrm{v} 1 \mathrm{~b}$ levels of the old rats with high anxiety. The high levels of $\mathrm{v} 1 \mathrm{~b}$ in young animals seems to accelerate helping behaviour whereas it has a slowing effect on helping behaviour for the elderly.

Following head trauma, empathy-like behaviour durations reached pre-trauma values on day 12 . There are some studies suggesting that the cognitive and functional disorders detected in the acute post-traumatic period improve in the subacute and chronic periods. Murine head trauma models indicated that deteriorations of spatial learning improved on day 28 and the neurological severity score ameliorated gradually until day $7(24,36)$. In another similar experimental model, first 3 days were defined as the acute phase of injury in the rat (14). We observed improvements in behaviour after day 3 .

Magnesium in plasma can enter brain tissue by passing through the blood-brain barrier into the extracellular compartment or by passing through the choroid plexus into the cerebrospinal fluid (13). The transition of magnesium from outside to the interior of the cell and $\mathrm{Mg}^{2+}$ homeostasis occurs by passive transport, primary and secondary active transport systems $(2,7)$. The manner with which to increase the magnesium carrying potential of these transport systems is not yet clear. In our previous study, we observed that independent of dose, magnesium acetyl taurate entered brain cells more effectively than other forms of magnesium (magnesium citrate, magnesium malate and magnesium glycinate) (3). However, in our previous study, the effectiveness of magnesium acetyl taurate in brain tissue was not measured.
In rat retinal and optic nerve injuries, the magnesium acetyl taurate form has been observed to prevent morphological nerve damage and apoptosis (26). Consistent with these studies, we demonstrated that the magnesium acetyl taurate prevents morphological damage and apoptosis in traumatic brain injuries. In addition, this form was found to be more effective with behaviour alterations and hormone preservation than the other magnesium compounds (magnesium sulphate and magnesium citrate).

In the Mg taurate group, we recorded that the vasopressin and v1b receptor levels in the amygdala were significantly higher compared to the trauma group. Since there was a correlation between duration and vasopressin and v1b levels, the increase of vasopressin and $\mathrm{v} 1 \mathrm{~b}$ receptors in the Mg taurate group may have contributed to the improvements in helping behaviour.

We observed that $\mathrm{v} 1$ receptor levels had not changed in all the magnesium treated groups, but only in the magnesium acetyl taurate group. The increments of receptors in the Mg taurate group should not be associated with the replacement of abolished receptors because the receptor levels of the trauma group had not changed. This effect of magnesium acetyl taurate may be associated with the taurine stimulant effect on $\mathrm{v} 1 \mathrm{~b}$ expression. Taurine has many protective effects in cells such as being an antioxidant, intracellular calcium regulator, a membrane stabilizer, reducing endoplasmic reticulum stress, and has neuroprotective effects (in diseases like Parkinson's, Alzheimer's and Huntington's) $(8,19)$. The murine TBI model demonstrated that brain oedema and many inflammatory cytokines [such as monocyte chemotactic protein-1 (MCP1), tumour necrosis factor-alpha (TNF- $\alpha$ ), interferon-gamma (IFN- $\gamma)$ and interleukin-1-beta (IL-1 $\beta$ )] expressions were diminished with taurine (38). Perhaps taurine may have increased $\mathrm{v} 1 \mathrm{~b}$ expression by similar mechanisms. The cooperation of magnesium and taurine may also yield these effects. Acetylation of the amine group in taurate decreases the polarity of magnesium salt and transforms it into a more lipophilic state (8). Becoming more lipophilic may facilitate the crossover to biological membranes. Higher magnesium levels in tissues can lead to the stimulation of gene expressions such as $v 1 \mathrm{~b}$ by nuclear mechanisms $(1,20)$. Actually, compared to other magnesium forms, magnesium acetyl taurinate has been reported to be more effective in preventing neurological complications in Mg-deficient murine models $(4,5)$. In comparison to other forms, a combination of magnesium and taurine may have produced a more pronounced effect by creating a synergistic effect.

\section{CONCLUSION}

Following mild $\mathrm{TBI}$, we found a transient empathy-like behaviour deterioration without significant indications of anxiety and depression. Our study revealed that magnesium acetyl taurate improved the hormone levels, morphological damage and apoptosis in the brain following head trauma and ameliorated the empathy-like behaviour. The beneficial effects of magnesium acetyl taurate may be a consequence of its penetrating the biological membrane, decreasing the number of apoptotic cells and regulating the functions of living cells. 


\section{ACKNOWLEDGMENT}

This study was supported by the Dokuz Eylul University Scientific Research Coordination Unit (Project Number: 2018KB.SAG.052).

We would like to thank Joanne Aliye Noonan Kutup who contributed to the English correction of the article, Erdem Erkoyun and Mustafa Delibaş for statistical analyses.

\section{- REFERENCES}

1. Ahmadi S, Naderifar $M$, Samimi M, Mirhosseini N, Amirani E, Aghadavod E, Asemi Z: The effects of magnesium supplementation on gene expression related to inflammatory markers, vascular endothelial growth factor, and pregnancy outcomes in patients with gestational diabetes. Magnes Res 31:131-142, 2018

2. Arjona FJ, de Baaij JHF: CrossTalk opposing view: CNNM proteins are not $\mathrm{Na}+/ \mathrm{Mg} 2+$ exchangers but $\mathrm{Mg} 2+$ transport regulators playing a central role in transepithelial $\mathrm{Mg} 2+(\mathrm{re})$ absorption. J Physiol 596:747-750, 2018

3. Ates M, Kizildag S, Yuksel O, Hosgorler F, Yuce Z, Guvendi G, Kandis S, Karakilic A, Koc B, Uysal N: Dose-dependent absorption profile of different magnesium compounds. Biol Trace Elem Res 192:244-251, 2019

4. Bac P, Herrenknecht C, Binet P, Durlach J: Audiogenic seizures in magnesium-deficient mice: Effects of magnesium pyrrolidone-2-carboxylate, magnesium acetyltaurinate, magnesium chloride and vitamin B-6. Magnes Res 6:11-19, 1993

5. Bac P, Herrenknecht C, Pages N, Dupont C, Durlach J: Reversible model of magnesium depletion induced by systemic kainic acid injection in magnesium-deficient rats: I-Comparative study of various magnesium salts. Magnes Res 9:281-291, 1996

6. Benedictus MR, Spikman JM, van der Naalt J: Cognitive and behavioral impairment in traumatic brain injury related to outcome and return to work. Archives of Physical Medicine and Rehabilitation 91:1436-1441, 2010

7. Beyenbach KW: Transport of magnesium across biological membranes. Magnesium and Trace Elements 9:233-254, 1990

8. Bidri M, Choay P: Taurine: A particular aminoacid with multiple functions. Annales Pharmaceutiques Francaises 61:385-391, 2003

9. Busingye DS, Turner RJ, Vink R: Combined magnesium/ polyethylene glycol facilitates the neuroprotective effects of magnesium in traumatic brain injury at a reduced magnesium dose. CNS Neuroscience \& Therapeutics 22:854-859, 2016

10. Cook NL, Corrigan F, van den Heuvel C: The role of magnesium in CNS injury. In: Vink R, Nechifor M (eds). Magnesium in the Central Nervous System. University of Adelaide Press (c), 2011

11. de Sousa A, McDonald S, Rushby J, Li S, Dimoska A, James C: Why don't you feel how I feel? Insight into the absence of empathy after severe traumatic brain injury. Neuropsychologia 48:3585-3595, 2010

12. Eslinger PJ: Neurological and neuropsychological bases of empathy. European Neurology 39:193-199, 1998
13. Ghabriel MN, Vink R: Magnesium transport across the bloodbrain barriers. In: Vink R, Nechifor M (eds). Magnesium in the Central Nervous System. University of Adelaide Press (c), 2011

14. Guo S, Zhou D, Zhang M, Li T, Liu Y, Xu Y, Chen T, Li Z: Monitoring changes of docosahexaenoic acid-containing lipids during the recovery process of traumatic brain injury in rat using mass spectrometry imaging. Scientific Reports 7:5054, 2017

15. Han JH, Tabak BA, Meyer ML, Castle E, Dutcher JM, Irwin MR, Lieberman MD, Eisenberger NI: PT710. Vasopressin increases empathic responding among those high in primary psychopathy. Int J Neuropsychopharmacol 19:58-59, 2016

16. Heath DL, Vink R: Magnesium sulphate improves neurologic outcome following severe closed head injury in rats. Neuroscience Letters 228:175-178, 1997

17. Heath DL, Vink R: Optimization of magnesium therapy after severe diffuse axonal brain injury in rats. The Journal of Pharmacology and Experimental Therapeutics 288:13111316, 1999

18. Hsieh TH, Kang JW, Lai JH, Huang YZ, Rotenberg A, Chen KY, Wang JY, Chan SY, Chen SC, Chiang YH, Peng CW: Relationship of mechanical impact magnitude to neurologic dysfunction severity in a rat traumatic brain injury model. PloS One 12(5):e0178186, 2017

19. Jakaria M, Azam S, Haque ME, Jo SH, Uddin MS, Kim IS, Choi DK: Taurine and its analogs in neurological disorders: Focus on therapeutic potential and molecular mechanisms. Redox Biol 24:101223, 2019

20. Jamilian M, Samimi M, Faraneh AE, Aghadavod E, Shahrzad HD, Chamani M, Mafi A, Asemi Z: Magnesium supplementation affects gene expression related to insulin and lipid in patients with gestational diabetes. Magnes Res 30:71-79, 2017

21. Jiang Y, Platt ML: Oxytocin and vasopressin increase maledirected threats and vocalizations in female macaques. Scientific Reports 8:18011, 2018

22. Jonkman K, Dahan A, van de Donk T, Aarts L, Niesters M, van Velzen M: Ketamine for pain. F1000Res 6:F1000, 2017

23. Karakilic A, Kizildag S, Kandis S, Guvendi G, Koc B, Camsari GB, Camsari UM, Ates M, Arda SG, Uysal N: The effects of acute foot shock stress on empathy levels in rats. Behavioural Brain Research 349:31-36, 2018

24. Khalin I, Jamari NLA, Razak NBA, Hasain ZB, Nor MABM, Zainudin MHBA, Omar AB, Alyautdin R: A mouse model of weight-drop closed head injury: Emphasis on cognitive and neurological deficiency. Neural Regen Res 11:630-635, 2016

25. Kohler I, Meier R, Busato A, Neiger-Aeschbacher G, Schatzmann U: Is carbon dioxide (CO2) a useful short acting anaesthetic for small laboratory animals? Laboratory Animals 33:155-161, 1999

26. Lambuk L, Jafri AJ, Arfuzir NN, lezhitsa I, Agarwal R, Rozali KN, Agarwal P, Bakar NS, Kutty MK, Yusof AP, Krasilnikova A, Spasov A, Ozerov A, Ismail NM: Neuroprotective effect of magnesium acetyltaurate against NMDA-induced excitotoxicity in rat retina. Neurotoxicity Research 31:31-45, 2017 
27. Lee SW, Jang MS, Jeong SH, Kim H: Exploratory, cognitive, and depressive-like behaviors in adult and pediatric mice exposed to controlled cortical impact. Clinical and Experimental Emergency Medicine 6:125-137, 2019

28. Marmarou A, Foda MA, van den Brink W, Campbell J, Kita $H$, Demetriadou K: A new model of diffuse brain injury in rats. Part I: Pathophysiology and biomechanics. Journal of Neurosurgery 80:291-300, 1994

29. McDonald BC, Flashman LA, Saykin AJ: Executive dysfunction following traumatic brain injury: Neural substrates and treatment strategies. Neuro Rehabilitation 17:333-344, 2002

30. McKee JA, Brewer RP, Macy GE, Phillips-Bute B, Campbell KA, Borel CO, Reynolds JD, Warner DS: Analysis of the brain bioavailability of peripherally administered magnesium sulfate: A study in humans with acute brain injury undergoing prolonged induced hypermagnesemia. Critical Care Medicine 33:661-666, 2005

31. Milders M: Relationship between social cognition and social behaviour following traumatic brain injury. Brain Inj 33(1):6268, 2019

32. Munivenkatappa A, Agrawal A, Shukla DP, Kumaraswamy $D$, Devi Bl: Traumatic brain injury: Does gender influence outcomes? Int J Crit IIIn Inj Sci 6:70-73, 2016

33. Mychasiuk R, Farran A, Angoa-Perez M, Briggs D, Kuhn D, Esser $\mathrm{MJ}$ : A novel model of mild traumatic brain injury for juvenile rats. J Vis Exp 94:51820, 2014

34. Oddo M, Crippa IA, Mehta S, Menon D, Payen JF, Taccone FS, Citerio G: Optimizing sedation in patients with acute brain injury. Crit Care 20:128, 2016

35. Sato N, Tan L, Tate K, Okada M: Rats demonstrate helping behavior toward a soaked conspecific. Animal Cognition 18:1039-1047, 2015

36. Shishido H, Ueno M, Sato K, Matsumura M, Toyota $Y$, Kirino $\mathrm{Y}$, Tamiya T, Kawai N, Kishimoto Y: Traumatic brain injury by weight-drop method causes transient amyloid-beta deposition and acute cognitive deficits in mice. Behav Neurol 2019:3248519, 2019

37. Siopi E, Llufriu-Daben G, Fanucchi F, Plotkine M, MarchandLeroux C, Jafarian-Tehrani M: Evaluation of late cognitive impairment and anxiety states following traumatic brain injury in mice: The effect of minocycline. Neuroscience Letters 511:110-115, 2012

38. Su Y, Fan W, Ma Z, Wen X, Wang W, Wu Q, Huang H: Taurine improves functional and histological outcomes and reduces inflammation in traumatic brain injury. Neuroscience 266:5665, 2014
39. Szczepankiewicz A, Leszczynska-Rodziewicz A, Pawlak J, Rajewska-Rager A, Wilkosc M, Zaremba D, DmitrzakWeglarz M, Skibinska M, Hauser J: Epistatic interaction between CRHR1 and AVPR1b variants as a predictor of major depressive disorder. Psychiatric Genetics 23:239-246, 2013

40. Tabak BA, Meyer ML, Castle E, Dutcher JM, Irwin MR, Han $\mathrm{JH}$, Lieberman MD, Eisenberger NI: Vasopressin, but not oxytocin, increases empathic concern among individuals who received higher levels of paternal warmth: A randomized controlled trial. Psychoneuroendocrinology 51:253-261, 2015

41. Temkin NR, Anderson GD, Winn HR, Ellenbogen RG, Britz GW, Schuster J, Lucas T, Newell DW, Mansfield PN, Machamer JE, Barber J, Dikmen SS: Magnesium sulfate for neuroprotection after traumatic brain injury: A randomised controlled trial. The Lancet Neurology 6:29-38, 2007

42. Thomas TC, Colburn TA, Korp K, Khodadad A, Lifshitz J: Frontiers in neuroengineering translational considerations for behavioral impairment and rehabilitation strategies after diffuse traumatic brain injury. In: Kobeissy FH (ed). Brain Neurotrauma: Molecular, Neuropsychological, and Rehabilitation Aspects. Boca Raton (FL): CRC Press/Taylor \& Francis (c), 2015

43. Vink R, McIntosh TK, Demediuk P, Weiner MW, Faden Al: Decline in intracellular free $\mathrm{Mg} 2+$ is associated with irreversible tissue injury after brain trauma. The Journal of Biological Chemistry 263:757-761, 1988

44. Williams C, Wood RL: Alexithymia and emotional empathy following traumatic brain injury. Journal of Clinical and Experimental Neuropsychology 32:259-267, 2010

45. Wood RL, Williams C: Inability to empathize following traumatic brain injury. J Int Neuropsychol Soc 14:289-296, 2008

46. Wu N, Shang S, Su Y: The arginine vasopressin V1b receptor gene and prosociality: Mediation role of emotional empathy. Psych J 4:160-165, 2015

47. Yuksel O, Ates M, Kizildag S, Yuce Z, Koc B, Kandis S, Guvendi G, Karakilic A, Gumus H, Uysal N: Regular aerobic voluntary exercise increased oxytocin in female mice: The cause of decreased anxiety and increased empathy-like behaviors. Balkan Medical Journal 36:257-262, 2019

48. Zappala G, Thiebaut de Schotten M, Eslinger PJ: Traumatic brain injury and the frontal lobes: What can we gain with diffusion tensor imaging? Cortex; A Journal Devoted to the Study of the Nervous System and Behavior 48:156-165, 2012 